\title{
Assessing Si-based anodes for Ca-ion batteries: electrochemical decalciation of $\mathrm{CaSi}_{2}$
}

\author{
A. Ponrouch ${ }^{1}$, D. Tchitchekova ${ }^{1}$, C. Frontera ${ }^{1}$, F. Bardé2, M. E. Arroyo-de Dompablo ${ }^{3, *}$ \\ and M. R. Palacín ${ }^{1}$ \\ ${ }^{1}$ Institut de Ciència de Materials de Barcelona (ICMAB-CSIC) Campus UAB, E-08193 Bellaterra, \\ Catalonia, (Spain) \\ ${ }^{2}$ Toyota Motor Europe, Research \& Development 3, Advanced Technology 1, Technical Centre, Hoge \\ Wei 33 B, B-1930 Zaventem, (Belgium). \\ ${ }^{3}$ Malta Consolider Team, Departamento de Química Inorgánica, Universidad Complutense de Madrid, \\ 28040 Madrid, (Spain) \\ *Corresponding author: e.arroyo@quim.ucm.es
}

\begin{abstract}
Density Functional Theory (DFT) calculations are used to investigate basic electrochemical characteristics of Si-based anodes in Calcium Ion Batteries (CIBs). The calculated average voltage of $\mathrm{Ca}$ alloying with fcc-Si to form the intermetallic $\mathrm{Ca}_{\mathrm{x}} \mathrm{Si}$ phases $(0.5<\mathrm{x} \leq 2)$ is of $0.4 \mathrm{~V}$, with a volume variation of $306 \%$. Decalciation of the lower $\mathrm{Ca}$ content phase, $\mathrm{CaSi}_{2}$, is predicted at an average voltage between $0.57 \mathrm{~V}$ (formation of $\mathrm{Si}-\mathrm{fcc}, 65 \%$ volume variation) and $1.2 \mathrm{~V}$ (formation of metastable deinserted-Si phase, 29\% volume variation). Experiments carried out in conventional alkyl carbonate electrolytes do evidence that electrochemical "decalciation" of $\mathrm{CaSi}_{2}$ is possible at moderate temperatures. The decalciation process from $\mathrm{CaSi}_{2}$ is confirmed by different characterization techniques.
\end{abstract}

Keywords: $\mathrm{Ca}$-ion batteries, $\mathrm{Si}$ anode, $\mathrm{CaSi}$ alloys, $\mathrm{CaSi}_{2}$ 


\section{Introduction}

Concerns on Li availability have prompted the search for suitable alternatives to rechargeable lithiumion battery (LIBs) technologies. Among these, batteries based on multivalent charge carriers $\left(\mathrm{M}^{\mathrm{n}+}\right)$ can exhibit advantages in terms of energy density since for a certain amount of $\mathrm{M}$ carriers the capacity is doubled $(n=2)$ or tripled $(n=3)$ when compared to single valent carriers like $\mathrm{Li}^{+} \mathrm{or} \mathrm{Na}^{+}$. Calcium is an attractive candidate $[1,2,3]$ due to its low cost, natural abundance and low reduction potential. We have recently reported on the feasibility and reversibility of calcium plating in conventional alkyl carbonate electrolytes at moderate temperatures [4] which opens the way to the development of a new rechargeable battery technology using calcium anodes. Yet, the theoretical capacity of $\mathrm{Ca}$ is 1340 $\mathrm{mAh} / \mathrm{g}$, and the exploration of alternative anodes based on intercalation or alloy reactions with higher capacities is a must to open as much research avenues as possible for the new calcium based battery technology (CIBs).

Alloying electrodes have shown to exhibit large capacities with lithium [5] and are also starting to be investigated with sodium and magnesium $[6,7]$. A recent publication reported on a tin anode for a Caion system utilizing manganese hexacianoferrate as the cathode, although no detailed characterization was provided on the tin electrode reaction mechanism [8]. The electrochemical formation of Si-based alloys with calcium has, to the best of our knowledge, not been investigated to date. Yet, in light of the existing knowledge on the Ca-Si phase diagram [9], it seems that it could be feasible. Table I lists the theoretical specific capacity for $\mathrm{Ca}_{\mathrm{x}} \mathrm{Si}$ alloys; a maximum theoretical capacity of $3818 \mathrm{mAh} / \mathrm{g}$ could be achieved reacting one mole of $\mathrm{Si}$ with two moles of $\mathrm{Ca}$ ions. The lower $\mathrm{Ca}$ content phase, $\mathrm{CaSi}_{2}$ with a theoretical specific capacity of $557 \mathrm{mAh} / \mathrm{g}$, is commercially available and thus an interesting starting point to investigate the possibilities of Si-based anodes for Ca batteries. In this work we perform first principles calculations at the Density Functional Theory (DFT) level to extract basic electrochemical 
characteristics of Si-based anodes in CIBs. Encouraged by the DFT results, the intermetallic $\mathrm{CaSi}_{2}$ is tested in Ca cells.

\section{Methodology}

Computational. Total energies of $\mathrm{Ca}$, fcc-Si, deinserted-Si, $\mathrm{Ca}_{2} \mathrm{Si}_{1} \mathrm{Ca}_{5} \mathrm{Si}_{3}, \mathrm{CaSi}$, and $\mathrm{CaSi}_{2}$ (see table I) have been calculated using VASP program (Vienna Ab-initio Simulation Program). [12] Density Functional Theory (DFT) calculations were performed within the General Gradient Approximation (GGA), with the exchange and correlation functional form developed by Perdew, Burke, and Ernzerhof (PBE). [13] The energy cut off for the plane wave basis set was fix at a constant value of $500 \mathrm{eV}$ throughout the calculations. The integration in the Brillouin zone is done on an appropriate set of $k$-points determined by the Monkhorts-Pack scheme. All crystal structures were fully relaxed and the final energies of the optimized geometries were recalculated to correct the changes in the basis set of wave functions during relaxation.

Experimental. Two-electrode Swagelok cells were assembled in an Ar-filled glove box. The working electrode consisted of a powder mixture of $\mathrm{CaSi}_{2}$ (Aldrich), with $30 \%$ of carbon black (Super P, Timcal Switzerland) on an aluminium current collector. The electrolyte used was $0.45 \mathrm{M} \mathrm{Ca}\left(\mathrm{BF}_{4}\right)_{2}$ in EC:PC (50/50 wt. \%), which enables Ca plating/stripping at moderate temperatures [4]. When compared to standard redox potential of the $\mathrm{Ca}^{2+} / \mathrm{Ca}^{0}$ vs. NHE, a negative potential shift was recorded and found to be close to $0.8 \mathrm{~V}[4,14]$ For sake of clarity all potentials reported are denoted as V vs. $\mathrm{Ca}^{2+} / \mathrm{Ca}_{\text {passivated }}$ in the manuscript. Galvanostatic Cycling with Potential Limitation (GCPL) and Cyclic Voltammetry (CV, $0.05 \mathrm{mV} / \mathrm{s}$, between 2 and $3.5 \mathrm{~V}$ vs. $\left.\mathrm{Ca}^{2+} / \mathrm{Ca}_{\text {passivated }}\right)$ were carried out at $100^{\circ} \mathrm{C}$ using a Bio-Logic VMP3 potentiostat. After testing, the electrochemical cell was dismantled inside an Arfilled glove box, the powder was scratched from the working electrode and introduced in a borosilicate glass capillary $(\phi=0.3 \mathrm{~mm})$ for Synchrotron X-ray powder diffraction (SXRPD) at MSPD beamline 
(Mythen detector, $\lambda=0.61971 \AA$ ) at ALBA synchrotron. [15] Scanning Electron Microscopy (SEM) studies on $\mathrm{CaSi}_{2}$ powder electrodes before and after electrochemical testing were performed using a Quanta 200 ESEM FEG FEI microscope equipped with an energy-dispersive X-ray spectrometer (EDS). Average particle sizes were estimated from SEM images as a mean over 90 randomly chosen particles.

\section{Results and discussion}

Table I lists crystallographic details of the calculated $\mathrm{Ca}_{\mathrm{x}} \mathrm{Si}$ alloys and fcc-Si (the thermodynamically stable form of $\mathrm{Si}$ at $25^{\circ} \mathrm{C}$ ). Figure 1 shows the calculated voltage-composition curve for fcc-Si alloying with $\mathrm{Ca}$. The total volume variation when going from fcc-Si to $\mathrm{Ca}_{2} \mathrm{Si}$ is of $306 \%$ at an average voltage of $0.37 \mathrm{~V}$. In short, the calculated voltage profile and volume variation follow the same characteristics encountered in the Li-Si system. [16] This makes appealing the exploration of $\mathrm{Si}$ anodes for calcium based batteries. While in-depth investigations of the Si anode are underway, in this communication we focus on the possible decalciation of $\mathrm{CaSi}_{2}$. The dealloying process of $\mathrm{CaSi}_{2}$ to produce fcc-Si is predicted at $0.57 \mathrm{~V}$, with a volume contraction of $65 \%$ (see figure 1). With this large volume variation, it is reasonable to think that decalciation of $\mathrm{CaSi}_{2}$ at moderate temperatures could originate a metastable-Si phase, rather than the fcc-Si.

The crystal structure of the layered intermetallic $\mathrm{CaSi}_{2}$ (S.G. R-3m) is shown in figure 1 . We have calculated the energy of the related deinserted $\mathrm{Si}$-phase. The deinsertion of all $\mathrm{Ca}$ ions from $\mathrm{CaSi}_{2}$ would occur at an average voltage of $1.2 \mathrm{~V}$ (figure 1, in blue) with volume variation of $29 \%$ due to a condensation of the Si-layers (see table I). The deinserted-Si structure is notoriously less stable (0.62 eV/atom.) than the fcc-Si. Therefore, even if Ca deinsertion from $\mathrm{CaSi}_{2}$ would be achieved during the first charge of the $\mathrm{Ca} / / \mathrm{CaSi}_{2}$ cell, there would be a strong driven force for the unstable "deinserted-Si framework" to transform to a more stable fcc-Si phase upon cycling.

In summary, DFT calculations indicate that the decalciation of $\mathrm{CaSi}_{2}$ to form a Si phase is possible at a maximum voltage of $1.2 \mathrm{~V}$ (formation of metastable deinserted-Si framework) and at a minimum voltage of $0.57 \mathrm{~V}$ (formation of the most stable form, fcc-Si). Voltages between $1.2 \mathrm{~V}$ and $0.57 \mathrm{~V}$ 
would represent a situation where the decalciation process has produced a Si-phase less stable than fcc-Si but more stable than the deinserted-framework.

The electrochemical performance of $\mathrm{CaSi}_{2}$ was investigated by GPLC at $\mathrm{C} / 100$ rate (1C being one $\mathrm{Ca}^{2+}$ inserted in one hour), and the results are shown in figure 2e. Signatures of electrochemical activity (specific capacity of about $400 \mathrm{mAh} / \mathrm{g}$ (or ca. $570 \mathrm{mAh} /\left(\mathrm{g}\right.$ of $\left.\mathrm{CaSi}_{2}\right)$ considering that the pristine powder is a mixture of $70 \%$ of $\mathrm{CaSi}_{2}$ and $30 \%$ of $\mathrm{Si}$, see below) can be observed, with a pseudo plateau centred at ca. $2.8 \mathrm{~V}$ vs. $\mathrm{Ca}^{2+} / \mathrm{Ca}_{\text {passivated }}$ upon oxidation and at ca. $0.9 \mathrm{~V}$ vs. $\mathrm{Ca}^{2+} / \mathrm{Ca}_{\text {passivated }}$ upon reduction. A voltage hysteresis of roughly $1.9 \mathrm{~V}$ is observed, thus indicating the existence of a notorious overpotential in the system, which is enhanced on further oxidation thereby limiting the achievable capacity. These results are consistent with those derived from cyclic voltammetry experiments, shown in Figure $2 \mathrm{f}$ (dotted black line for first cycle). In order to confirm that this redox phenomenon is related to the active material itself and not to parasitic reactions involving the electrolyte, both pristine and oxidized electrodes were characterized by SEM, EDS and SXRPD.

Careful investigation of the pristine powder by SEM (figure 2a) and EDS indicates that it consists of a heterogeneous mixture of $\mathrm{CaSi}_{2}$ and $\mathrm{Si}$ (particles without any calcium are detected while others contain ca. $40 \%$ atomic percent of Ca). This is confirmed by SXRPD (see Figure 3), with semiquantitative analysis which renders a relative ratio of 70/30 wt. \%. As shown in figures $2 \mathrm{a}-\mathrm{d}$, the SEM micrographs indicate that the mean particle size of $\mathrm{CaSi}_{2}$ decreases after oxidation from 7.3 to $2.6 \mu \mathrm{m}$ while by EDS a diminution in the average atomic $\mathrm{Ca}$ content in the calcium containing particles to reach ca. $7 \%$ atomic percent (which would be close to $\mathrm{Ca}_{0.15} \mathrm{Si}_{2}$ ) is observed. Thus, both EDS and SEM observations are in agreement with electrochemical calcium extraction from $\mathrm{CaSi}_{2}$. This is also confirmed by SXRPD, as the peaks corresponding to $\mathrm{CaSi}_{2}$ have decreased in intensity leaving almost only the peaks corresponding to $\mathrm{Si}$ in the oxidized sample (see Figure 3). The relative intensities of the Si peaks have changed after extraction, which we attribute to a texture modification as detected by SEM. 
The characterization of the charged electrode (SEM, EDS, SPXRD) confirms the decalciation of $\mathrm{CaSi}_{2}$, which is observed at $2.8 \mathrm{~V}$ vs $\mathrm{Ca}^{2+} / \mathrm{Ca}_{\text {passivated. }}$. From the experimental SPXRD we can infer that the decalciated phase is likely an amorphous compound which could further react with $\mathrm{Ca}$ at $0.9 \mathrm{~V}$ during the discharge of the cell. A confrontation with the calculated voltages of decalciation is difficult due to the large overpotential of the cell. However, the calculated voltage of the dealloying reaction to form fcc-Si, $(0.57 \mathrm{~V})$ seems too low compared to the observed voltages. The experimental voltage rather support that the decalciation of $\mathrm{CaSi}_{2}$ renders a $\mathrm{Si}$-phase less stable than fcc-Si (calculated voltage for the deinsertion mechanism is $1.2 \mathrm{~V}$ ). Further experimental work is certainly needed to fully elucidate the redox mechanism.

\section{Conclusions}

Although the reversible calcium plating/stripping has been recently enabled in $\mathrm{Ca}\left(\mathrm{BF}_{4}\right)_{2} / \mathrm{PC}: \mathrm{EC}$ electrolytes, higher specific capacities could be reached utilizing alternative alloy based anode materials. The calculated V-x curve of Ca alloying with fcc-Si to form the intermetallic $\mathrm{Ca}_{\mathrm{x}} \mathrm{Si}$ phases $(0.5<\mathrm{x} \leq 2)$, with an average voltage of $0.37 \mathrm{~V}$, makes appealing the investigation of Ca-Si alloys. Since the investigation of alloy formation is complex due to possible electrolyte decomposition at low potential, we have explored the electrochemical decalciation of $\mathrm{CaSi}_{2}$. DFT results indicate that the electrochemical decalciation reaction would be observed at different voltages depending on the formed Si-phase (fcc-Si $0.57 \mathrm{~V}$, deinserted $\mathrm{CaSi}_{2}$ structure $1.2 \mathrm{~V}$ ). Experiments carried out do confirm that electrochemical decalciation of $\mathrm{CaSi}_{2}$ is possible at moderate temperatures. Our combined experimental and computational investigation prove that $\mathrm{Ca}-\mathrm{Si}$ alloys can be electrochemically active as anode in Ca batteries, opening the way to the quest of alloy based electrodes for CIB. Much more work is certainly needed before being able to develop electrodes able to sustain large and reversible capacities. 
Acknowledgments: Authors are grateful to Dr. François Fauth for his assistance during data collection at ALBA synchrotron and to the Toyota Battery Research division at Higashi Fuji (M6) for financial support.

\section{References}

[1] M. Hayashi, H. Arai, H. Ohtsuka, Y. Sakurai., Electrochemical characteristics of calcium in organic electrolyte solutions and vanadium oxides as calcium hosts, J. Power Sources, 119 (2003), 617-620.

[2] G. G. Amatucci, F. Badway, A. Singhal, B. Beaudoin, G. Shandan, T. Bowmer, I. Plitz, T. Chapman, R. Jaworski, Investigation of Yttrium and Polyvalent Ion Intercalation into Nanocrystalline Vanadium Oxide, J. Electrochem. Soc., 148 (2001), 940-950

[3] J. P. Pereira-Ramos, R. Messina, J. Perichon, Electrochemical Formation of Vanadium Pentoxide Bronzes M x V 2 O 5 in Molten Dimethylsulfone J. Electrochem. Soc. 135 (1988) 3050-3057

[4] A. Ponrouch, C. Frontera, F. Barde, M. R. Palacin., Towards a Calcium-based rechargeable battery, Nat. Mater. 15 (2016) 169.

[5] L. Croguennec, M.R. Palacin, Recent achievements on inorganic electrode materials for Lithiumion batteries, J. Am. Chem. Soc. 137 (2015) 3140-3156.

[6] A. Darwiche, C. Marino, M.T. Sougrati, B. Fraise, L. Stievano, L. Monconduit, Better cycling performances of bulk $\mathrm{Sb}$ in Na-ion batteries compared to Li-ion systems: an unexpected electrochemical mechanism., J. Am. Chem. Soc. 134 (2012) 20805-20811

[7] T. S. Arthur, N. Singh, M. Matsui, A high energy-density tin anode for rechargeable magnesiumion batteries, Electrochem. Commun. 16 (2012) 103-106.

[8] A.L. Lipson, B. Pan, S.H. Lapidus, C. Liao, J.Y. Vaughey and B.J. Ingram, Rechargable Ca-ion Batteries; A New Energy Storage System, Chem. Mater., 27 ( 2015) 8442-8447

[9] P. Manfrinetti, M.L. Fornasini and A. Palenzona, The Phase diagram of the Ca-Si system, Intermetallics, 8, (2000), 223-228 
[10] P. Debye and P. Scherrer, Interferenzen an regellos orientierten Teilchen im Roentgenlicht, Physikalische Zeitschrift (1916) 17, 277-283

[11] A.L. Spek,PLATON, A Multipurpose Crystallographic Tool, J. Appl. Cryst., (2003) 36, 7-13.

[12] G. Kresse and J. Furthmuller, Efficiency of ab-initio total energy calculations for metals and semiconductors using a plane-wave basis set, Computer Matter. Science 6, (1996) 15-50

[13] J. P. Perdew, K. Burke, M. Ernzerhof,, Generalized Gradient Approximation Made Simple, Physical Review Letters 77 (1996) 3865-3868

[14] D. Aurbach, R. Skaletsky, Y. Gofer, The Electrochemical Behavior of Calcium Electrodes in a Few Organic Electrolytes, J. Electrochem. Soc. 138, (1991) 3536-3545.

[15] F. Fauth, I. Peral, C. Popescu, M. Knapp, The new Material Science Powder Diffraction beamline at ALBA Synchrotron, Powder Diffraction 28 (S2) (2013) S360-S370.

[16] B.A. Boukamp, G.C. Lesh and R.A. Huggins, All-Solid Lithium Electrodes with MixedConductor Matrix , J. of Electrochem. Soc, 128, (1981) 725-729. 


\section{Figure Captions}

Figure 1. Calculated composition-voltage profiles. The black line corresponds to the calciation of fccSi following an alloying mechanism in which intermetallics $\mathrm{Ca}_{\mathrm{x}} \mathrm{Si}$ are formed. The blue line accounts for the deinsertion of $\mathrm{Ca}$ ions from the layered $\mathrm{CaSi}_{2}$. The inset shows the schematic crystal structure of $\mathrm{CaSi}_{2}$ ( $\mathrm{Si}$ in grey, $\mathrm{Ca}$ in blue). The calculated volume expansions are given as percentage, either associated to each voltage step (in bold) or referred to the Si phase (in italic).

Figure 2. SEM micrographs (backscattered electrons mode) of $\mathrm{CaSi}_{2}$ powder electrode (a,b) before and (c,d) after cyclic voltammetry at $0.05 \mathrm{mV} / \mathrm{s}$ to $3.5 \mathrm{~V}$ vs. $\mathrm{Ca}^{2+} / \mathrm{Ca}$ at $100^{\circ} \mathrm{C}$. (e) Capacity vs. potential profile from GCPL (C/100 rate) and (f) cyclic voltammograms $(0.05 \mathrm{mV} / \mathrm{s})$ of $\mathrm{CaSi}_{2}$ electrode in a 2electrode Ca cell operating at $100^{\circ} \mathrm{C}$.

Figure 3. SXRPD patterns corresponding to the pristine electrode prepared with the commercial $\mathrm{CaSi}_{2}$ before (bottom) and the electrode after oxidation to $3.5 \mathrm{~V}$ vs. $\mathrm{Ca}^{2+} / \mathrm{Ca}$ at $100^{\circ} \mathrm{C}$ (upper). Miller indices of diffraction peaks of $\mathrm{CaSi}_{2}$ (roman type) and $\mathrm{Si}$ (italic type) are shown. Other peaks (marked as *) correspond to unidentified impurity(ies) already present in the pristine commercial sample. Note that the pristine powder is indeed a mixture of $\mathrm{CaSi}_{2}(70 \%)$ and $\mathrm{Si}(30 \%)$. 
Table I.- Theoretical Specific capacity and crystallographic information of Ca-Si compounds

\begin{tabular}{|c|c|c|c|c|c|}
\hline Phase & $\begin{array}{c}\text { Molar mass } \\
(\mathrm{g} / \mathrm{mol})\end{array}$ & $\begin{array}{c}\text { Theoretical } \\
\text { Specific capacity } \\
\text { (mAh/g) }\end{array}$ & S.G. & $\begin{array}{c}\text { Experimental } \\
\text { Lattice } \\
\text { Parameters } \\
\text { (Å) [9], [10] }\end{array}$ & $\begin{array}{c}\text { Calculated } \\
\text { Lattice } \\
\text { Parameters } \\
\text { (Å) }\end{array}$ \\
\hline fcc-Si & 28.086 & 3818 & $F d-3 m$ & $a=5.43^{*}$ & $a=5.468$ \\
\hline Deinserted_Si & 28.086 & - & $R-3 m^{\&}$ & - & $\begin{array}{l}a=3.86 \\
c=24.36\end{array}$ \\
\hline $\begin{array}{c}\mathrm{CaSi}_{2} \\
\left(\mathrm{Ca}_{0.5} \mathrm{Si}\right)\end{array}$ & 96.250 & 557 & $R-3 m$ & $\begin{array}{l}a=3.86 \\
c=30.07\end{array}$ & $\begin{array}{l}a=3.84 \\
c=31.68\end{array}$ \\
\hline $\mathrm{CaSi}$ & 68.164 & 787 & $\mathrm{Cmcm}$ & $\begin{array}{c}\mathrm{a}=4.56 \\
\mathrm{~b}=10.73 \\
\mathrm{c}=3.89\end{array}$ & $\begin{array}{c}\mathrm{a}=4.54 \\
\mathrm{~b}=10.74 \\
\mathrm{c}=3.90\end{array}$ \\
\hline $\begin{array}{c}\mathrm{Ca}_{5} \mathrm{Si}_{3} \\
\left(\mathrm{Ca}_{5 / 3} \mathrm{Si}\right)\end{array}$ & 314.65 & 852 & $I 4 / \mathrm{mcm}$ & $\begin{array}{l}a=7.64 \\
c=14.87\end{array}$ & $\begin{array}{l}a=7.63 \\
c=14.79\end{array}$ \\
\hline $\mathrm{Ca}_{2} \mathrm{Si}$ & 108.24 & 991 & Pnma & $\begin{array}{l}a=7.69 \\
b=4.82 \\
c=9.03\end{array}$ & $\begin{array}{l}\mathrm{a}=7.60 \\
\mathrm{~b}=4.82 \\
\mathrm{c}=9.04\end{array}$ \\
\hline
\end{tabular}

\footnotetext{
${ }^{\&}$ Symmetry analysis was performed with the PLATON software [11]
} 


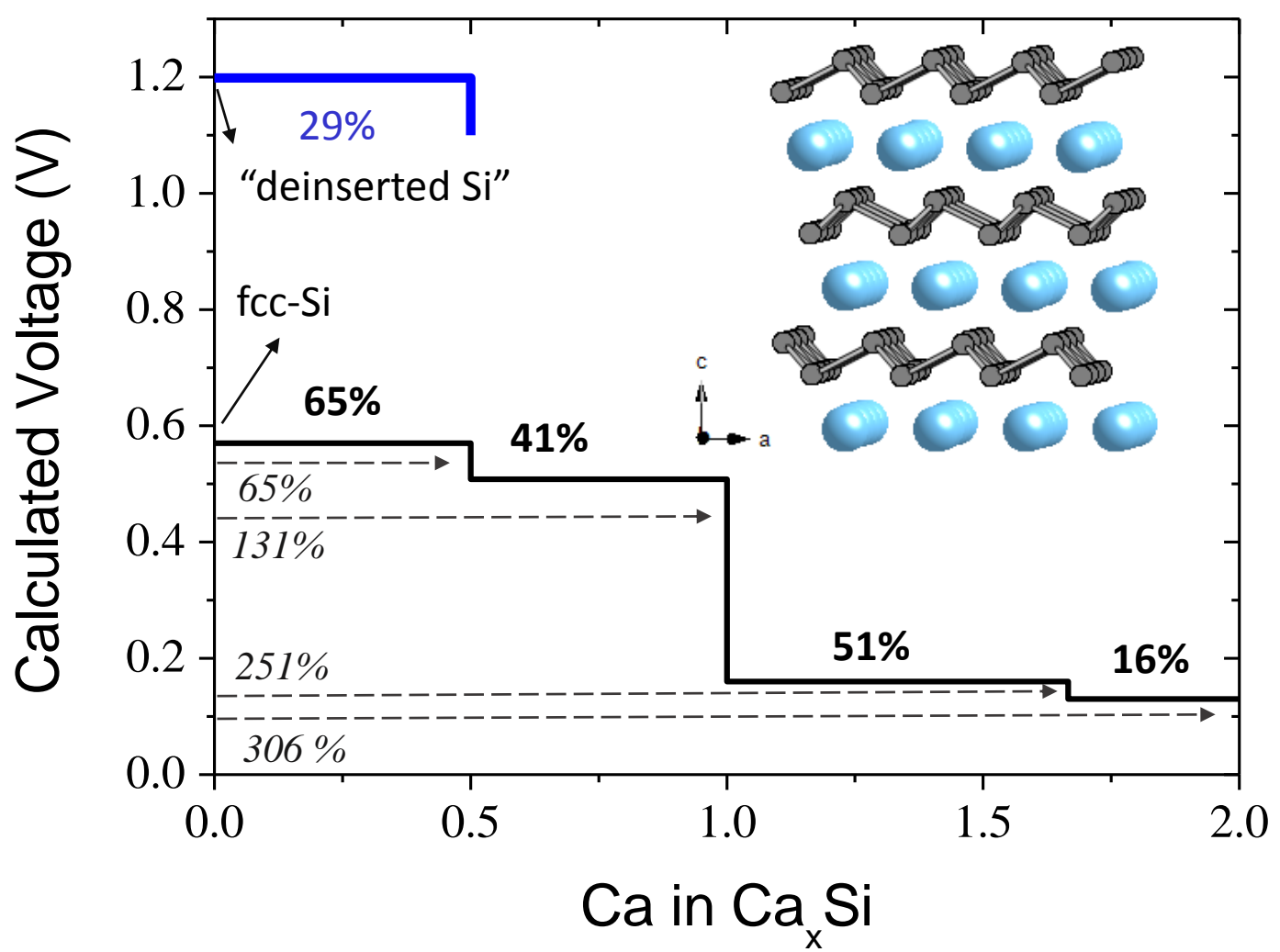

Ponrouch et al. Figure 1 

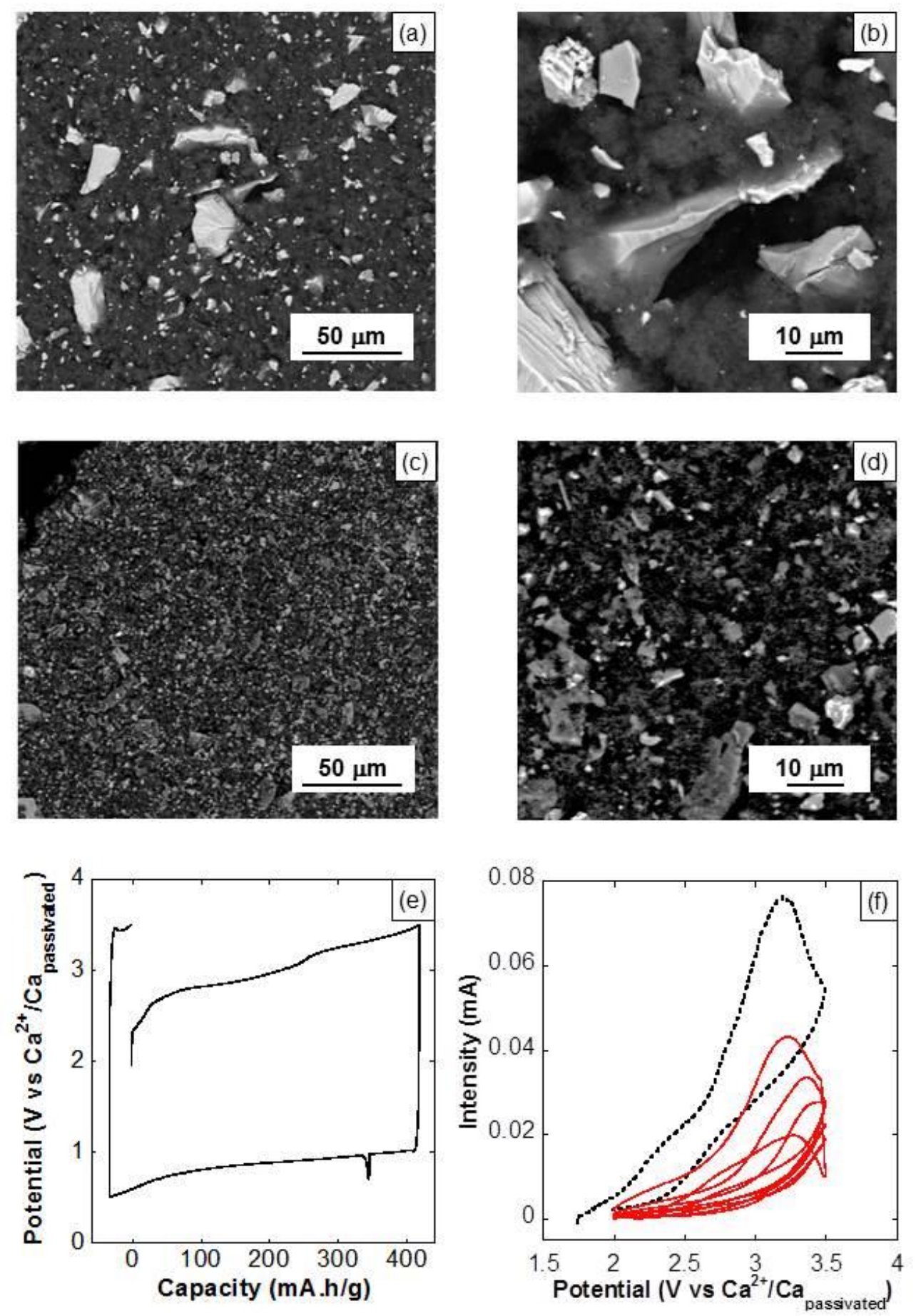

Ponrouch et al. Figure 2 


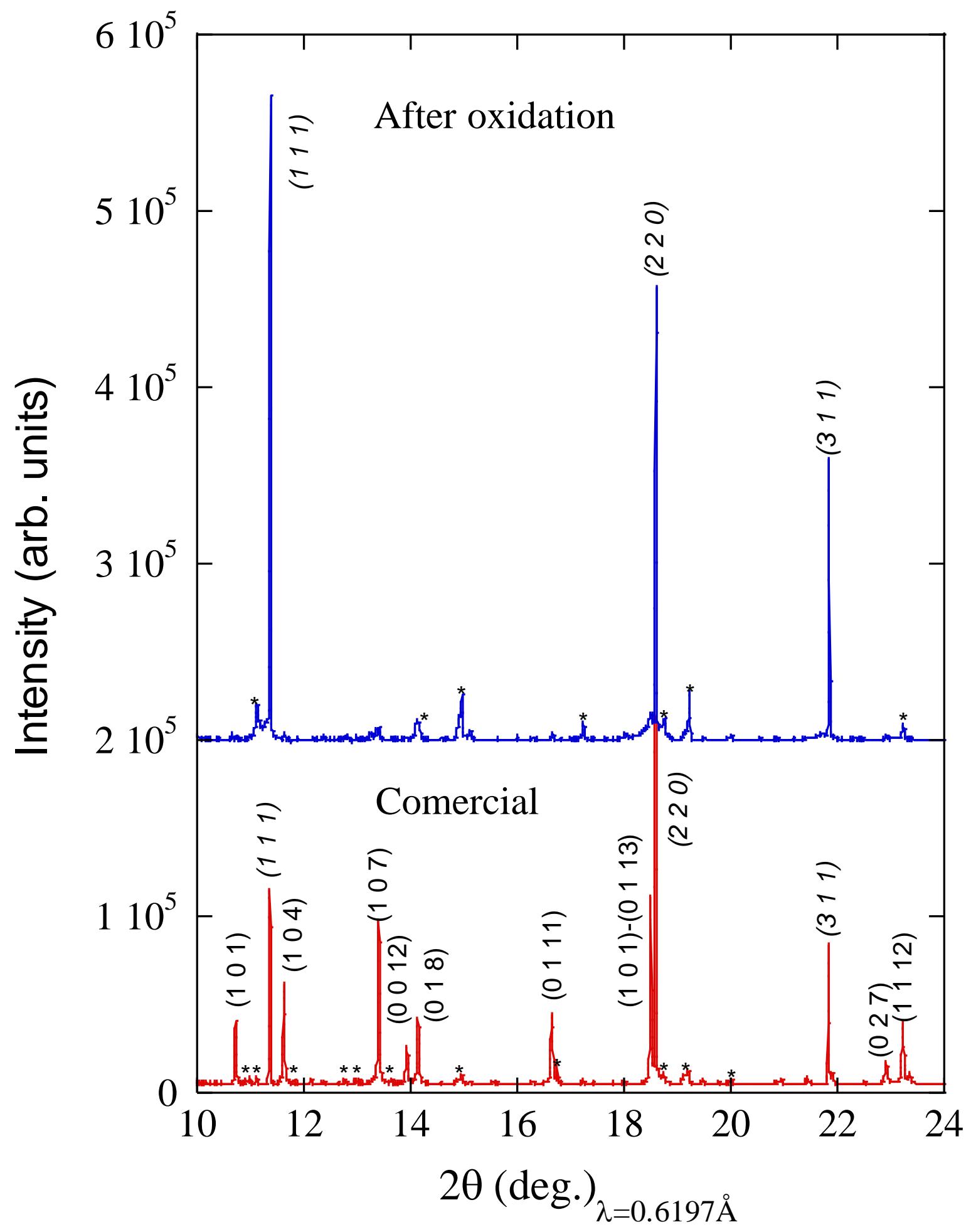

Ponrouch et al. Figure 3 